\title{
CONFIGURAÇÕES LOCAIS DA REDE SOCIOASSISTENCIAL DO SUAS PARA A PROTEÇÃO SOCIAL DE PESSOAS COM DEFICIÊNCIA E SUAS FAMÍLIAS: OLHARES A PARTIR DOS CENTROS-DIA DE REFERÊNCIA NA REGIÃO NORDESTE DO BRASIL
}

\author{
Joseane Santos Santana \\ Graduada em Serviço Social \\ Universidade Federal do Recôncavo da Bahia \\ Cachoeira - Bahia - Brasil \\ joseanesantana1989@hotmail.com \\ Edgilson Tavares Araújo \\ Doutor em Serviço Social \\ Universidade Federal do Recôncavo da Bahia \\ Cachoeira - Bahia - Brasil \\ edgilson@ufrb.edu.br
}

\section{RESUMO}

Este trabalho teve como objetivo analisar as configurações locais da rede socioassistencial Sistema Único de Assistência Social (SUAS) para proteção social de pessoas com deficiência e suas famílias, atendidas em Centros-Dia implementados nas capitais do Nordeste do Brasil. Dos nove Centros-dia previstos para implementação nesta região, foram analisados os cinco implementados entre 2012 e 2015. Trata-se de um estudo com metodologia qualitativa, com aplicação de um instrumento inspirado em Bulhosa (2015), que previa desenhos das representações das percepções dos técnicos e gestores dos serviços sobre as configurações da rede em torno do Centro-Dia, identificando os fluxos de oferta e demanda de atendimentos e acompanhamentos. De modo complementar, utilizaram-se dados secundários de entrevistas e grupos focais realizados numa pesquisa avaliativa sobre a implementação destes serviços, realizada anteriormente. O Centro-Dia é assumido como o mais novo instrumento de políticas públicas do Suas, buscando-se assim compreender como é idealizada/definida a rede em que este foi inserido (discurso explícito) e como vem sendo vivenciada e implementada na prática (discurso implícito) (Lascoumes \& Le Galès, 2007, 2012). Os principais resultados apontam para múltiplos desenhos da Rede Suas em torno dos cinco Centros-dia pesquisados, com diferentes números de instituições e tipos de relação (oferta-demanda; frágil-forte), confirmando que, apesar do sistema ser único, este não é uniforme, operando serviços e articulações em rede, de modo ainda fragilizadas. Tal fragilidade é demonstrada pelas variadas capacidades técnica, política e de financiamento em cada contexto local. Tanto nas articulações intrassetoriais entre os Centros-dia com os demais equipamentos do SUAS, como as intersetoriais com outras políticas públicas, principalmente, saúde e educação, percebe-se frágil articulação.

Palavras-chave: Centro-Dia; Pessoas com deficiência; Proteção social; Rede de políticas públicas; SUAS.

\section{LOCAL CONFIGURATIONS OF THE SOCIAL ASSISTANCE NETWORKING OF SUAS FOR THE SOCIAL PROTECTION OF PEOPLE WITH DISABILITIES AND THEIR FAMILIES: LOOKS FROM THE DAY-CENTERS REFERENCE IN THE NORTHEAST REGION OF BRAZIL}

\section{ABSTRACT}

This study aimed to analyze the network local configurations of the Sistema Único de Assistência Social (SUAS) for social protection of people with disabilities and their families, attended in Day Center in the Northeast of Brazil. We analyzed five Day Centers in the region of the existing nine, implemented between 2012 and 201. This study is qualitative, with the application of an instrument inspired in Bulhosa (2015), which provided drafts of representations of the technicians and managers' perceptions of the services on the policy networking settings around the Day Center, identifying supply flows and demand for care and monitoring. In a complementary tool, secondary data from interviews and focus groups were used in a previous evaluation of the implementation of those services. The Day Center is known as the newest instrument of public policies of SUAS. In this way, we seek to understand the conceived policy and networking in which it is inserted (explicit speech) and how it has been experienced and implemented (implicit discourse) (Lascoumes \& Le Gales, 2007, 2012). The main results point to multiple drawings of the SUAS network around the five Day Centers surveyed, with different numbers of institutions and types of relationship (supply-demand, fragile-strong), confirming that although the system is unique, it is not uniform, operating network services in still fragile style. Such fragility is demonstrated by the varied technical, political and financing capacities in each local. Intra-sectoral articulations between the Day Centers and other SUAS, as well as inter-sectoral links with other public policies, mainly health and education, show a fragile articulation.

Keywords: Day center; Networking policy; People with disabilities; Social protection; SUAS. 
Configurações locais da rede socioassistencial do SUAS, para a proteção social das pessoas com deficiência e suas famílias: olhares a partir dos Centros-Dia de referência na região Nordeste do

Brasil

\section{INTRODUÇÃO}

O Plano Nacional dos Direitos da Pessoa com Deficiência - Viver Sem Limite ratifica, no Brasil, a Convenção Internacional dos Direitos da Pessoa com Deficiência, da ONU (2007). Prevê, entre a suas ações interministeriais, a oferta de serviços sócio assistenciais por meio da abertura de 27 Centros-Dia de Referência para Pessoa com Deficiência e suas Famílias, no âmbito do Sistema Único de Assistência Social (Suas), sendo um em cada estado do país. Trata-se de um serviço especializado inovador para oferta de cuidados para jovens e adultos com todos os tipos de deficiência (idade de 16 a 59 anos), voltado para o aumento da autonomia, melhoria da convivência e dos vínculos familiares e comunitários, e desoneração do cuidador familiar. Desde 2012, o Governo Federal, em parceria com governos estaduais e municipais, vem implementando estes serviços sócio assistenciais no Suas.

As definições do problema público, da concepção conceitual e da gestão do instrumento Centro-dia foram feitas pela Governo Federal, por meio do Ministério do Desenvolvimento Social e Combate à Fome (MDS), com apoio de experts no tema da pessoa com deficiência, seguindo as prerrogativas do instrumento legal Tipificação Nacional de Serviço Socio assistenciais, no qual está previsto, desde 2009, o Serviço de Proteção Social Especial de Média Complexidade para Pessoas com Deficiência e suas Famílias, ofertado em Centro-dia ou unidades referenciadas. Criou-se, assim, uma modelização do problema público a ser enfrentado, neste caso, focado nas relações de dependência de cuidados de terceiros enquanto fator agravante de riscos e vulnerabilidades sociais para a pessoa com deficiência jovem e adulta. Trata-se, portanto, de uma visão particular do problema que pode ser posteriormente questionada por posicionamentos conflitantes (Lorenc Valcarce, 2005 apud Araújo, 2015). Deste modo, a partir da "janela de oportunidades" criada pelo Plano Viver Sem Limites, define-se e seleciona-se um problema, elabora-se uma agenda e uma alternativa de solução em política pública com a criação e implementação de um equipamento público para prestar serviços sócio assistenciais para pessoas com deficiência, tendo execução, direta ou indireta, financiada prioritariamente pelo Governo Federal e executada, de modo incremental, pelos municípios, dado o caráter inovador do serviço (Araújo, 2015).

As primeiras experiências de abertura deste equipamento surgiram em dezembro de 2012, sendo criadas Orientações Técnicas específicas e cofinanciamento pelo Governo Federal junto com os Governos Estaduais e Municipais para implementar 27 unidades, sendo uma por Estado. Porém, apesar da existência de recursos e institucionalidade (Araújo, 2015; Araújo, Boullosa, 2015), até dezembro de 2015, só haviam sido implementados 17 Centros-Dia, sendo atualmente, seis destes em capitais da Região Nordeste. A partir desta experiência, foi financiado, no âmbito do edital Mcti/CNPq/MDS/Sagi 024/2013, o projeto de pesquisa "Avaliação do processo de implementação dos Centros-Dia de Referência para a Pessoa com Deficiência e suas Famílias, no âmbito do Plano Viver Sem Limite, na Região Nordeste"1. O objetivo do referido projeto foi mapear e categorizar os principais dilemas e desafios (institucionais, políticos, técnicos, cognitivos e de gestão) para a efetiva implementação e funcionamento dos Centros-Dia de Referência para a Pessoa com Deficiência nas capitais da região nordeste, buscando apontar possíveis soluções. Os desafios identificados foram apontados a partir de quatro dimensões de análise (político-institucional, gestão, técnico-operacional e cognitivo) cruzadas com três níveis de problematização (gramática, institucionalidade e recursos). Assim, a problemática que origina este trabalho, tem por base alguns resultados que surgiram a partir da pesquisa anteriormente realizada e citada (Edital Mcti/CNPq/MDS/Sagi 024/2013) pontuando, principalmente, alguns dos desafios identificados:

a) na dimensão político-institucional, que buscou responder sobre a qualidade e a sustentabilidade da pactuação e como se dá a organização da burocracia, chama-se a atenção para o desafio da baixa articulação da rede socioassistencial;

b) na dimensão gestão, aponta-se, entre outros problemas, a pouca clareza sobre os fluxos do serviço;

c) na técnico-operacional, que evidenciou qual a compreensão do serviço socioassistencial e como se dá sua implementação, destaca-se a pouca clareza sobre referenciamento e contrarreferenciamento dos serviços ofertados.

d) na dimensão cognitiva, que analisou os modelos de aprendizagem inerentes aos processos desencadeados, chama-se a atenção para o desafio compreensão do serviço socioassistencial.

Além destes quatro desafios, foram apontados outros, porém, estes trazem à tona uma das macroquestões que são colocadas para os sistemas federativos de políticas públicas. Nesse estudo, especificamente, o foco foram as questões voltadas para as configurações locais do trabalho em rede do Suas

Revista de Gestão Social e Ambiental - RGSA, São Paulo, v. 11, n. 3, p. 73-91, set./dez. 2017. 
nas seis capitais do Nordeste que já implementaram o Centro-Dia, desde 2012: São Luís, Teresina, Fortaleza, Aracaju, João Pessoa e Natal. As três primeiras implementaram os Centros-Dia com execução indireta, cuja gestão está sob responsabilidade de organizações privadas, sem fins lucrativos, em parceria com o município; as demais são executadas diretamente pelas prefeituras e seus respectivos órgãos gestores.

Logo, a problemática que origina este trabalho, tem por base algumas questões que surgiram a partir da pesquisa avaliativa realizada, pontuando alguns dos desafios identificados, principalmente, referentes a dimensão político-institucional, que buscou responder sobre a qualidade e a sustentabilidade da pactuação e como se dá a organização da burocracia, chamando-se a atenção para a categoria referente ao desafio da articulação da rede socioassistencial.

Diante de diferentes formas de articulação nos níveis locais, o Centro-Dia conta com uma infinidade de relacionamentos possíveis e necessários para o seu funcionamento, demandando processos de compreensão mais profundos de como se dá o desenvolvimento de tais articulações. Pretendeu-se, portanto, questionar mais sobre a execução do serviço nos diferentes municípios com foco nas suas fragilidades sobre as articulações da rede, a questão levantada foi: Quais as diferentes configurações locais da Rede Socioassistencial Suas para a proteção social de pessoas com deficiência e famílias atendidas em CentrosDia de Referência nas capitais da Região Nordeste?

O objetivo geral da pesquisa apresentada neste paper foi analisar as configurações locais da rede socioassistencial do Suas para proteção social de Pessoas com Deficiência e Famílias, atendidas em CentrosDia de Referência implementados em diferentes capitais da Região Nordeste. Os objetivos específicos foram apontar e comparar as diferentes percepções e configurações sobre o funcionamento da rede socioassistencial para pessoas com deficiência e famílias atendidas nos Centros-Dia; identificar os principais desafios e problemas na articulação na Rede Socioassistencial Suas nas capitais analisadas, que impactam na proteção social de pessoas com deficiência e suas famílias.

Partindo do arcabouço teórico-metodológico sobre policy networks, considerando o Centro-Dia como um instrumento de política pública ${ }^{2}$, supõe-se que existe independência entre discursos explícitos (planejados e oficializados em normas e orientações) e os implícitos (vivenciados e praticados no cotidiano) (Lascoumes, Lé Gales, 2007, 2012). Buscou-se perceber o que se diz, o que se compreende e o que se faz nos Centros-Dia no contexto da Rede Socioassistencial do Suas. Nesse contexto, tentou-se compreender a natureza coletiva de governo dos problemas públicos que envolvem as pessoas com deficiência e alternativas escolhidas para resolvê-los. Desta forma, identifica-se como os problemas e soluções para o desenvolvimento dos Centros-Dia foram definidos (discurso explícito) e como vem sendo praticados (vividos) no sentido do trabalho em rede.

Metodologicamente, foram feitas algumas escolhas teórico-metodológicas apoiando-se na policy network analysis (análise de redes de políticas públicas) que trata da ideia de analisar as políticas públicas a partir de retículos de atores, públicos e privados, dotados de recursos quantitativamente e qualitativamente diversos, que operam em um espaço definido pelo problema de policy. Deste modo, transfere-se o foco analítico de qualquer tipo de "estrutura" para o conjunto de "relações" mais ou menos intensas, largas, institucionalizadas etc. (Giuliani, 1998). Busca, assim, dar conta dos "porquês" e "como" os atores individuais e coletivos agem pela descrição das ligações entre eles dentro de estruturas que emergem tal relação e que direcionam os comportamentos e práticas. Este tipo de análise permite visualizar a complexidade da ação pública em distintas atividades manejáveis, tendo um valor descritivo da rede políticoadministrativa nos processos de implementação de políticas públicas. Assim, apresenta-se como uma alternativa "[...] nà noção de política pública elaborada exclusivamente sobre parâmetros técnicos, legais e administrativos" (Procopiuck, 2013, p.215).

Para atingir os objetivos desta pesquisa, foi preciso associar alguns procedimentos metodológicos nas diferentes etapas desenvolvidas nesta pesquisa:

1) revisão bibliográfica sobre policy network e Suas com atenção também para os documentos oficiais, tais como a Tipificação Nacional de Serviços Socioassistenciais, Plano Nacional Viver Sem Limites, Política Nacional de Assistência, entre outros;

2) construção e aplicação de um instrumento de pesquisa inspirado em Bulhosa (2015), em que se pedia para que a coordenação e a equipe técnica de cada Centro-Dia listassem todas as organizações públicas e privadas (da Assistência Social, da Saúde, da Educação, da Cultura, dos Esportes e Lazer, ONGs, órgãos de defesa de direitos, etc.) com quem mantêm ou deveria manter relacionamentos em rede, para depois distribuí-las em um quadro a ser desenhado, tendo como centralidade o Centro-Dia, buscando mostrar as afinidades e articulações. Esta representação deveria ter linhas e setas cheias (forte articulação) ou pontilhadas (frágil articulação) de sentido único (oferta OU demanda por serviços) ou de duplo sentido 
Configurações locais da rede socioassistencial do SUAS, para a proteção social das pessoas com deficiência e suas famílias: olhares a partir dos Centros-Dia de referência na região Nordeste do

(oferta E demanda por serviços), demonstrando como se dariam as articulações e parcerias existentes ou que deveriam existir, conforme demonstrado na figura 1. Solicitava-se, ainda, que, depois de feito o desenho da rede, fosse elaborado um texto explicativo de como se dava tais relações.

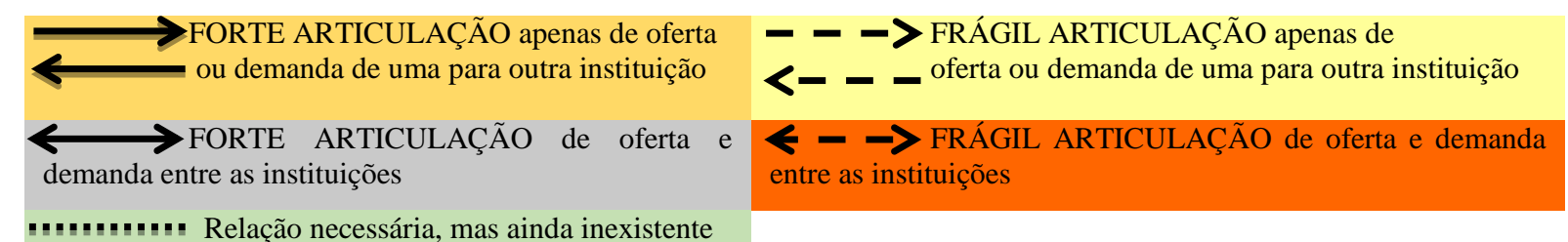

Figura 1: Legenda de instrumento de pesquisa sobre configurações da rede de proteção social para pessoas com deficiência

Fonte: Autoria própria.

Tais instrumentos foram enviados e preenchidos entre novembro e dezembro de 2015, via e-mail, para cada um dos cinco Centros-Dia implementados no Nordeste, sendo também reforçado o pedido e a explicação via telefone. Tais equipamentos públicos já tinham passado pela pesquisa de avaliação de implementação, anteriormente citada, entre janeiro de 2014 e julho de 2015. Todos devolveram o instrumento, mas nenhum deles encaminhou o texto descritivo explicando o fluxo da rede criado. Tal fato demonstrou a necessidade de se retomar as análises referentes aos conteúdos específicos coletados da pesquisa de avaliação anterior que, especificamente, tratavam da articulação da rede Socioassistencial envolvida com o Centro-dia. Assim, foram analisadas tais questões nas transcrições de: cinco grupos focais realizados com as equipes técnicas (coordenador, assistente social, psicólogo, terapeuta ocupacional, cuidadores); cinco entrevistas com os coordenadores dos Centros-dia; três entrevistas com coordenadoras de Creas; cinco entrevistas com os gestores municipais da Assistência Social; dois diretores da Proteção Social Especial que representaram os gestores. Todas essas entrevistas foram gravadas (855') e transcritas na íntegra e, em seguida, feita análise de conteúdo.

A análise dos instrumentos de pesquisa foi feita, inicialmente, observando elementos em comum nas articulações entre os equipamentos listados e o Centro-Dia em todas as representações da configuração local das redes. Associado a isso, buscou-se identificar conteúdos e temas relevantes nas entrevistas e grupos focais que demonstram as características conjunturais e demais elementos que consubstanciam as configurações locais de cada Centro-Dia na Rede Socioassistencial do Suas.

Além desta introdução, o conteúdo está apresentado em mais quatro partes: (2) a rede socioassistencial do Suas e o Centro-Dia de Referência para Pessoas com Deficiência e suas Famílias; (3) as configurações locais da Rede Socioassistencial do Suas expressas pelos Centros-Dia de Referência: convergências e distinções; (4) Os pontos convergentes e distinções nas configurações locais da rede; (5) considerações finais.

\section{A REDE SOCIOASSISTENCIAL DO SUAS COMO POLICY NETWORK E O CENTRO-DIA DE REFERÊNCIA PARA PESSOAS COM DEFICIÊNCIA E SUAS FAMÍLIAS}

Os estudos sobre policy network foram iniciados nas décadas de 1970 e 1980, mas ganharam relevância na década de 1990, ao possibilitarem a análise da formulação de políticas públicas dentro da União Europeia, de modo a caracterizar um novo sistema de governança baseado em negociações entre governos e outros atores públicos e privados. Assume-se, assim, uma perspectiva relacional dos estudos sobre policy, com foco nos atores, seus interesses e, principalmente, suas relações como fatores explicativos, quantitativos ou qualitativos, utilizados enquanto uma mera metáfora ou como uma definição clara que posteriormente é operacionalizada (Raab, Kenis, 2007; Giuliani, 1998).

O termo rede, no âmbito dos policy studies, aparece como um novo paradigma para dar conta da "arquitetura da complexidade" (Simon apud Kenys, Schneider, 1991) existente nas sociedades modernas ou como o principal dispositivo para reintegrar sistemas diferenciados de atores (Raab, Kenis, 2007). Para Castells (2000, p.497), rede é "[...]um conjunto de nós interconectados. Nó é o ponto no qual uma curva se entrecorta." Fazem parte de uma nova "morfologia social das sociedades" e altera substancialmente as operações e os resultados de produção, poder e cultura. Os dois componentes básicos de todas as análises de 
rede são um conjunto de objetos (chamados de nós, posições ou atores) e um conjunto de relações entre esses objetos (chamados bordas, laços ou links) (Kenis, Schneider, 1991).

A rede é um instrumento promissor que oferta possibilidades de ir além da descrição das estruturas institucionais formais, mas para a análise dos diferentes atores políticos em relações de poder e comunicação, cooperação e conflito, parcerias e cooptação. É certo que nenhuma política pública na atualidade vai ser contra a utilização deste termo, seja enquanto estrutura de governança ou necessidade de categorização. Isso se dá, principalmente, por três fatores: a) a transformação da realidade política; b) uma subsequente transformação do quadro conceitual e teórico na policy analisys; c) o crescente desenvolvimento de metodologias para análise estrutural das redes (Kenis, Schneider, 1991). De acordo com Raab e Kenis (2007), o termo policy network (rede de políticas públicas) tem sido usado com diferentes significados e analiticamente com diferentes propósitos, podendo-se identificar pelo menos três dimensões do conceito:

(1) rede como estrutura analítica e como ferramenta empírica - assume-se uma perspectiva particular de foco de análise sobre os atores, seus interesses e laços existentes e inexistentes entre si, criando, assim, um novo paradigma baseado em relações e não em atributos. A análise de rede, neste sentido, não se apoia num método estatístico neutro, tampouco numa teoria, mas como uma ferramenta empírica para descrever a estrutura social com base nas relações dos atores. É aplicada como um quadro analítico, que orienta as percepções empíricas na pesquisa sobre formulação e implementação de políticas públicas e direciona a percepção e a atenção dos pesquisadores para os atores e suas relações.

(2) rede como estrutura social - entende-se que a rede é uma estrutura social fluída e com características específicas que dependem de análise de questões econômicas, políticas e sociais, presumindo que os atores constroem ao longo do tempo relações de intercâmbio mais ou menos estáveis. Assim, os "nós" da rede representam atores públicos (ministérios, secretárias, equipamentos públicos etc.) e privados (ONGs, sindicatos, associações etc.). Neste sentido, na formulação da política pública, considera-se a predominância de um arranjo de relações comunicativas informais e relações de poder horizontais e descentralizadas e, sua análise, portanto, buscará revelar especificidades quanto as características estruturais.

(3) rede como forma de governança - esta abordagem integra lógicas da economia, das teorias organizacionais e da ciência política concebendo a rede como uma forma discreta de governança que, com o mercado e hierarquia, constitui um tipo ideal de coordenação, voltadas não apenas para o sistema de produção e intercâmbio, mas para a resolução de conflitos de modo legítimo, criar orientações gerais (cognitivas) e incentivar os diferentes atores. Os sistemas de governança apresentam características de uma rede ou representam um tipo misto e emergente de estrutura que produz resultados que não podem ser atribuídos ou controlados por apenas uma única organização.

Além destas três dimensões, os autores fazem referência a teoria de rede, mesmo havendo incertezas quanto a exatamente o que essa venha a ser, uma vez que a rede ora é uma variável dependente (objeto de estudo), ora como variável independente (resultados políticos comportamento organizacional etc.)

Seguindo tendências, o Brasil tem adotado, em todos os seus sistemas federativos de políticas públicas (saúde, educação, assistência social, cultura etc.), a perspectiva de trabalho de policy network, principalmente, enquanto estrutura social e como forma de governança. Deste modo, neste estudo compreende-se a importância de analisar a Rede Socioassistencial do Suas ou Rede Suas, numa perspectiva da rede também como estrutura analítica e ferramenta empírica, de modo a ter subsídios para analisar além do que está colocado nas normativas e orientações técnicas.

A Rede Suas diz respeito ao conjunto de equipamentos públicos e entidades privadas que desenvolvem projetos, planos, programas, ofertam serviços ou benefícios, relacionadas à Política de Assistência Social; ou o conjunto de entidades e de serviços realizados em parceria; ou o próprio conjunto de serviços socioassistenciais; ou o conjunto de intervenções sociais que incorporam as redes sociais, a rede socioassistencial e redes de outras políticas sociais. Para o Suas, o conceito posto é o de rede pública de serviços, programas, projetos e benefícios socioassistenciais que articulam a totalidade destes pelos diversos equipamentos públicos e das organizações privadas (Brasil, 2013), associando-os a uma nova estrutura social e forma de governança.

Compreender a Rede Suas como estrutura analítica e ferramenta empírica é buscar desvendar as qualidades das relações entre os atores diferentes em diferentes contextos socioterritoriais. A atenção se desloca da forma e estrutura para as percepções sobre papéis que a rede desempenha na ordenação das interações entre sujeitos diferentes com foco nas ofertas do Suas que pode ocorrer por meio de execução direta nos equipamentos públicos ou indireta pelas organizações da sociedade, mas que em ambos os casos deve fortalecer parcerias e alianças estratégicas (Araújo, 2015). 
Configurações locais da rede socioassistencial do SUAS, para a proteção social das pessoas com deficiência e suas famílias: olhares a partir dos Centros-Dia de referência na região Nordeste do

A Rede Suas está estruturada em dois níveis de proteção social. A Proteção Social Básica (PSB) com ofertas de serviços e benefícios socioassistenciais com função preventiva dos riscos e vulnerabilidades sociais, tendo os Centros de Referência em Assistência Social (Cras) como principal equipamento. A Proteção Social Especial (PSE) tem função protetiva atendendo pessoas em situação de vulnerabilidades e riscos agravados por violação de direitos. Essa se divide em PSE de Média Complexidade na qual existem ofertas para pessoas que ainda possuem vínculos familiares, cujo principal equipamento é o Centro de Referência Especializada em Assistência Social (Creas); e a PSE de Alta Complexidade que oferta serviços para aqueles sem vínculos familiares, tais como abrigos, residências inclusivas, repúblicas etc. Os Cras e Creas foram desenhados para serem os principais ofertantes, respectivamente, do Serviço de Proteção e Atendimento Integral à Família (Paif) e do Serviço de Proteção e Atendimento Especializado a Famílias e Indivíduos (Paefi). Houve grande expansão destes em todo o país, havendo 8.088 Cras e 2.372 Creas (Brasil, MDS, Censo Suas, 2014).

A complexidade do desenho institucional da Rede Suas envolve, além do Creas na PSE de Média Complexidade, mais de 215 Centros de Referência Especializados para População em Situação de Rua (Centro-Pop) e múltiplas ofertas em entidades privadas referenciadas. Como já apontado, mais recentemente, desde 2012, vem sendo abertos os mais novos equipamentos e serviços de Média Complexidade, voltados especificamente para pessoas com deficiência, os Centros-dia de Referência.

A Rede Suas, enquanto rede de políticas públicas (policy networking), é uma rede interssetorial e uma rede de serviços públicos institucionais, seguindo a classificação feita por Guará (1998). Isto se dá porque este sistema atende aos seguintes parâmetros: a) se estrutura a partir do espaço público governamental para satisfazer direitos garantidos na lei; b) abrange serviços e programas consagrados pelas políticas setoriais públicas de educação, saúde, assistência social etc.; c) têm como fundamento as relações formais e seu protagonista é o Estado; d) mantém padrões centralizadores, hierárquicos e sua dinâmica interna tende a fechá-las dentro de si próprias (Guará, 1998).

Para a compreensão e implementação de policy networks, tal como o Suas, é preciso responder analiticamente a necessidade de abandonar as estruturas formais do processo político-administrativo como sede natural da formulação e implementação das políticas públicas. Trata-se de compreender ideia de retículo de atores, públicos e privados, dotados de recursos quantitativamente e qualitativamente diversos, que operam em um espaço definido pelo problema de policy. Denotam, assim, de modo sugestivo, o fato de que o policy making process (processo de decisão política) inclui um amplo número de atores públicos e privados, proveniente de diferentes níveis e áreas funcionais do governo e da sociedade (Giuliani, 1998).

A Rede Suas, constituída como uma rede de políticas públicas, num primeiro momento, buscou expandir e institucionalizar diferentes equipamentos públicos, serviços, benefícios, programas e projetos, criando um grande puzzle de ofertas voltadas para a prevenção de riscos e vulnerabilidade sociais, bem como o aumento da capacidade protetiva do Estado para com os cidadãos. Assim, mais que quantificar as institucionalidades, é preciso qualificar e entender como estas se relacionam (ou não), planejam e gerem as demandas locais, compreendem e materializam a política social.

Nesta perspectiva da policy network, esse estudo assumiu o Centro-Dia como um instrumento de política pública da Assistência Social, implementado de forma descentralizada e cofinanciado por todos os entes federados. Trata-se, portanto, de um "nó" da rede que deve manter relações com outros "nós". A organização dos serviços ofertados em Centro-Dia deve considerar o suporte e apoio dos demais serviços do Suas, na PSB e PSE de Média e Alta Complexidade, da rede do Sistema Único de Saúde (SUS) e de outras instituições. Ao mesmo tempo, deve servir de referência para produção e difusão de conhecimentos para a qualificação do Suas, com vistas a assegurar a inclusão das pessoas com deficiência e suas famílias nos serviços tipificados ${ }^{3}$, na perspectiva da autonomia, do fortalecimento da convivência familiar e convivência comunitária (Brasil, 2012).

O objetivo principal do Centro-dia é ofertar o Serviço de Proteção Social à pessoa com deficiência em situação de dependência e à sua família, por meio de acolhida, escuta, informação, orientação e oferta de cuidados cotidianos, além de apoiar suas famílias no exercício da função protetiva, fortalecendo as redes comunitárias. Trata-se de um conjunto de serviços diurnos ofertados dentro de uma programação diária específica para atender as demandas de jovens e adultos (18 a 59 anos) com todos os tipos de deficiência (auditiva, visual, intelectual, física e múltipla), associadas ou não a síndromes e outras questões de saúde, com certo grau elevado de dependência, mas com algum nível de autonomia que possa propiciar melhor participação em serviços coletivos e atenções individualizadas por parte de cuidadores (Araújo, Cruz, 2013) e suas famílias, tendo este que retornar à sua residência após a oferta dos serviços planejados. Prioriza-se o 
atendimento a pessoas com deficiência e em situação de dependência e suas famílias, os beneficiários do BPC, em situação de pobreza e outras vulnerabilidades sociais, que estejam incluídos no Cadastro Único de Programas Sociais (CadÚnico).

Cada Centro-Dia deve atender, no máximo, 30 usuários por turno / tipo de atendimento, a ser definido pelos Planos Individuais e/ou Familiar de Atendimento propostos por uma equipe mínima multidisciplinar composta por um coordenador, um assistente social, um terapeuta ocupacional, um psicólogo e 10 cuidadores de nível médio (Brasil, 2012).

É importante destacar que o serviço ofertado em Centro-Dia deve ser referenciado a um Creas e ter relação de parceria com uma Equipe de Saúde Básica da Família e/ou ao Núcleo de Apoio a Saúde da Família (Nasf), do SUS. Por esta razão, a localização do imóvel deve considerar também a localização dos serviços do Suas e do SUS, como preconiza as Orientações Técnicas (Araújo; Cruz, 2013). Neste contexto, pressupõe-se, do ponto de vista do desenho da política pública, que, promover a estreita articulação entre os serviços do Suas, potencializa os efeitos do serviço especializado ofertado no Centro-Dia e contribui para a inclusão social dos seus usuários.

\section{AS CONFIGURAÇÕES LOCAIS DA REDE SOCIOASSISTENCIAL DO SUAS EXPRESSAS PELOS CENTROS-DIA DE REFERÊNCIA}

Nesta parte do texto, apresentamos e discutimos os principais resultados da pesquisa de campo, por meio das análises dos instrumentos encaminhados e respondidos pelas equipes dos 05 (cinco) Centros-dia em funcionamento na Região Nordeste do Brasil, pedindo para que desenhassem, descrevessem e explicassem as relações existentes entre o equipamento público e a policy network em cada contexto. Importante salientar que este estudo não foi feito com base nas tradicionais análises quantitativas sobre formação de redes, utilizando softwares estatísticos, mas, ousou-se na criação e testagem de um instrumento qualitativo, de simples compreensão a aplicação, que busca trazer, a partir de percepções dos atores envolvidos na rede, um quadro analítico que orienta as percepções empíricas sobre a implementação dos Centros-dia. Neste sentido, a atenção dos pesquisadores foi para a compreensão empírica da estruturação social da rede, seus atores e relações existentes ou que sejam necessárias existir.

Associado a análise dos desenhos da rede em nível local elaboradas pelas equipes de implementadores dos Centros-dia, buscou-se identificar conteúdos e temas relevantes nas entrevistas e grupos focais destes, que haviam sido realizadas meses antes na pesquisa de Avaliação da Implementação dos Centros Dia (CNPq/MDS), conforme citada anteriormente. Estas demonstram algumas especificidades conjunturais e outros elementos que consubstanciam as configurações locais de cada Centro-Dia na Rede Suas. A finalidade foi de compreender a estruturação e a existência de organicidade política e administrativa da cooperação da rede que tende a não ser simples e espontânea, assim como em outras policy networks.

$\mathrm{Na}$ apresentação das análises, optou-se por omitir os nomes dos Centros-Dia e das capitais nordestinas (sendo identificadas como A, B, C, D e E), bem como dos profissionais que participaram das entrevistas e grupos focais no sentido de tornar o mais fidedigno possível os resultados e preservar a identidade dos sujeitos da pesquisa. A seguir, apresentamos alguns dos principais resultados da pesquisa, tendo como base a descrição das redes feitas por cada Centro-dia.

Salienta-se que os cinco equipamentos pesquisados, apesar de se encontrarem em distintas capitais do Nordeste, estão aptos a implementar o serviço com o cofinanciamento dos governos federal e estadual.

O Centro-Dia da cidade A, pactuado entre os governos federal, estadual e municipal em novembro de 2012, sendo implementado imediatamente em dezembro de 2012, com execução direta, contava, no momento da pesquisa, com 42 usuários apontando, conforme consta na figura 2 , a percepção sobre as organizações que compõem a rede na qual está inserido. Trata-se de um serviço já existente que migrou para o formato de Centro-dia, o que pode, de certa forma, justificar o mais rápido tempo de implementação e, ao mesmo tempo, baixa articulação em rede. Em comparação aos demais fluxos recebidos, este foi o que apresentou o menor número de organizações listadas. Na Assistência Social, por exemplo, coloca-se a articulação com apenas três equipamentos, cuja relação ainda é bem fragilizada. Outro aspecto importante a ser citado é a relação com a saúde, cujo fluxo também traz apenas três organizações, dos quais a melhor relação é com o Centro de Atendimento Psicossocial (Caps). 


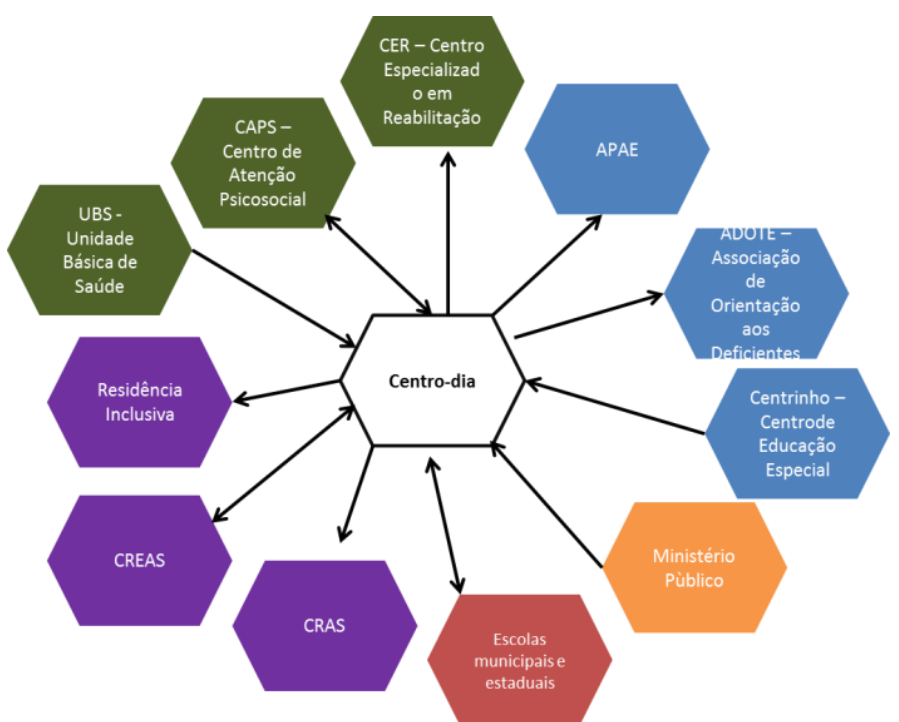

Figura 2: Configuração da Rede de Proteção Social a Pessoa com Deficiência atendida no Centro-Dia da Cidade A

Fonte: Autoria própria a partir da pesquisa de campo

De forma geral, este equipamento, apesar de ter uma clareza do que essas articulações na rede representam e da necessidade de cada uma delas, ainda encontra dificuldades para firmar estes laços:

A dificuldade no município mesmo acho que é essa questão da integração, da socialização. Nos núcleos de saúde, há uma dificuldade, até porque a demanda é muito alta ainda. Então, essa parceria a gente já está buscando [...]Apesar de conversar com os diretores, com os postos de saúde, mas há dificuldade pelo município, pela demanda que já existe de eles estarem recebendo a nossa demanda, acho que essa é nossa dificuldade maior. (Grupo Focal/Assistente Social - Centro-Dia A).

Esta dificuldade apontada pela equipe técnica também é identificada pela gestora do equipamento, vista como uma necessidade de desenvolver essa articulação com a rede e demais políticas setoriais: "A gente fala muito de articulação, mas a gente que tem que procurar, tem que buscar. Muita parte da rede não funciona. A rede não funciona! Muita coisa é porque a gente botou isso na cabeça, disse que não funciona e não vai atrás." (Entrevista Gestora do Centro-Dia A).

É interessante ressaltar que a dimensão "número e estabilidade de atores envolvidos" na rede é destacada na literatura no sentido de preservar a especialização ou a influência da própria rede. As "modalidades de adesão e a intensidade das interações" também são variáveis importantes de analisar (Giuliani, 1998) Neste caso, o Centro-dia A, enquanto ator da "centralidade" da rede, possui ainda baixa "conectividade" diante da alta "complexidade" da oferta de diferentes serviços que requer (Alter, Hage, 1993). Apesar de demonstrar relações "fortes" com apenas 11 instituições, sendo apenas com três relações de oferta e demanda, das quais duas da rede de Assistência Social e uma da Saúde. 


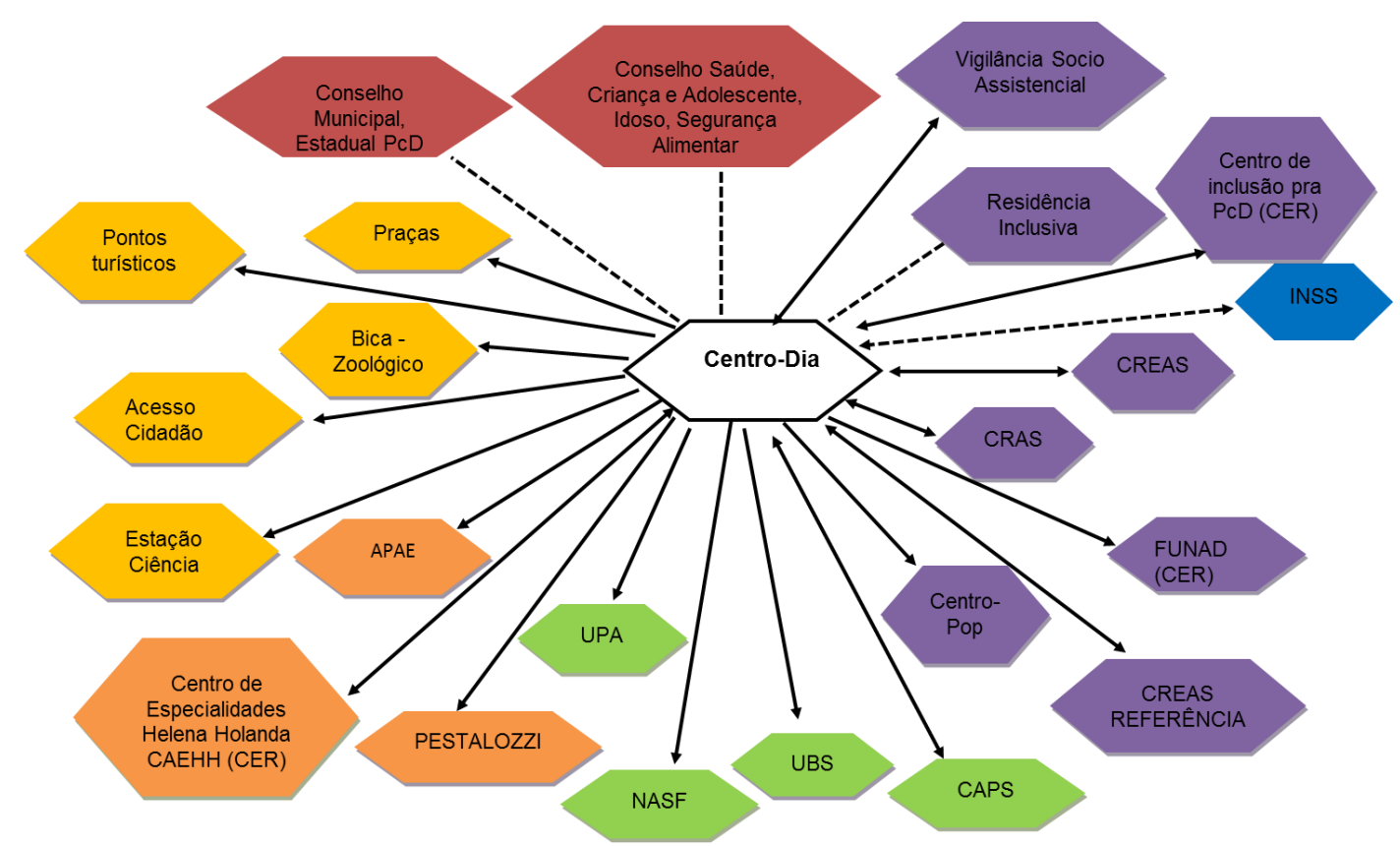

Figura 3: Configuração local da Rede de Proteção Social a Pessoa com Deficiência atendida no Centro-Dia da Cidade B

Fonte: Autoria própria a partir da pesquisa de campo

O Centro-Dia da cidade B, pactuado em julho de 2012 e seis meses depois inaugurado, em dezembro daquele ano, com execução direta, contava apenas com 12 usuários, quando a demanda prevista era de 30 por turno. Pela figura 3, demonstra ter uma boa percepção da rede em que o equipamento está inserido, bem como das necessidades de firmar laços com as instituições do Suas, do SUS e outras redes. Apesar do baixo número de usuários, vem tendo a oportunidade de corrigir alguns rumos e criar novas estratégias de ação. Isso aparece na fala da coordenadora do Centro-Dia B, quando a mesma foi questionada sobre como é que está a questão da articulação da rede: "Melhorou bastante, até porque, como a gente já tá há dois anos, a gente já tem mais conhecimento sobre os serviços e aí a gente não tá tendo nenhuma dificuldade" (Coordenadora do Centro-Dia B).

O fluxo desenhado aponta para relações com sete equipamentos da Assistência Social. Em sua maioria, as ligações entre eles são boas, embora apresentem a necessidade de firmar ligações com a Residência Inclusiva que ainda não existe, por exemplo. A relação com outras políticas setoriais também apresenta dificuldades. Embora no desenho apareça, como aos fluxos fortes, com equipamentos de saúde, demonstrados como processos apenas de demandas do Centro-dia para estes como boas relações, nas falas isso é apresentado como desafio:

(...) essa é a nossa dificuldade. Muitas vezes, a psicóloga identifica essa questão do transtorno mais avançado e tenta fazer essa interlocução com a saúde e já tem uma barreira com isso da saúde para fazer essa avaliação vai ser aplicada também, a gente tem essa dificuldade nesse processo mais rápido (Entrevista Gestora do Creas - Centro-Dia B).

É interessante ressaltar ainda que são listados na rede do Centro-dia B, relações com vários equipamentos de cultura e esporte, bem como, pontuada a fraca relação com órgãos de controle social.

Mesmo quando se há uma maior clareza sobre a atuação da rede, daquilo que existe e que deve existir, percebe-se que a segmentação das competências públicas e a contaminação destas com formas privadas de gestão dos poderes, deixam pouco frutífera a tradicional relação entre Estado (controle vertical), mercado (equilíbrio espontâneo) e sociedade civil (Giulianni, 1998)

No equipamento da cidade C, pactuado em novembro de 2012 e implementado desde 2014, com execução direta, atualmente conta apenas com nove usuários. Esse baixo número de atendidos aparece como reflexo da falta de comunicação interna na própria rede. Destaca-se na figura 4, uma grande necessidade de articulação, principalmente com organizações que já trabalham com a temática e até mesmo órgão de defesa do direito da pessoa com deficiência. Entretanto, isso não aparece tanto nas falas das entrevistas. A gestora 
Configurações locais da rede socioassistencial do SUAS, para a proteção social das pessoas com deficiência e suas famílias: olhares a partir dos Centros-Dia de referência na região Nordeste do

Brasil

do Creas de Referência destaca que tem se esforçado para funcionar a rede e avalia que tem fluído o processo:

A gente até tem circulado bem [...] Temos buscado a rede de saúde direto, porque os nossos casos de violação de direito estão no nosso território e no território das unidades [de saúde] também... [...]Geralmente o Ministério Público chama a gente... Então isso tem facilitado o serviço que tem fluído bem e melhorou bastante. (Gestora do Creas - Centro-Dia C).

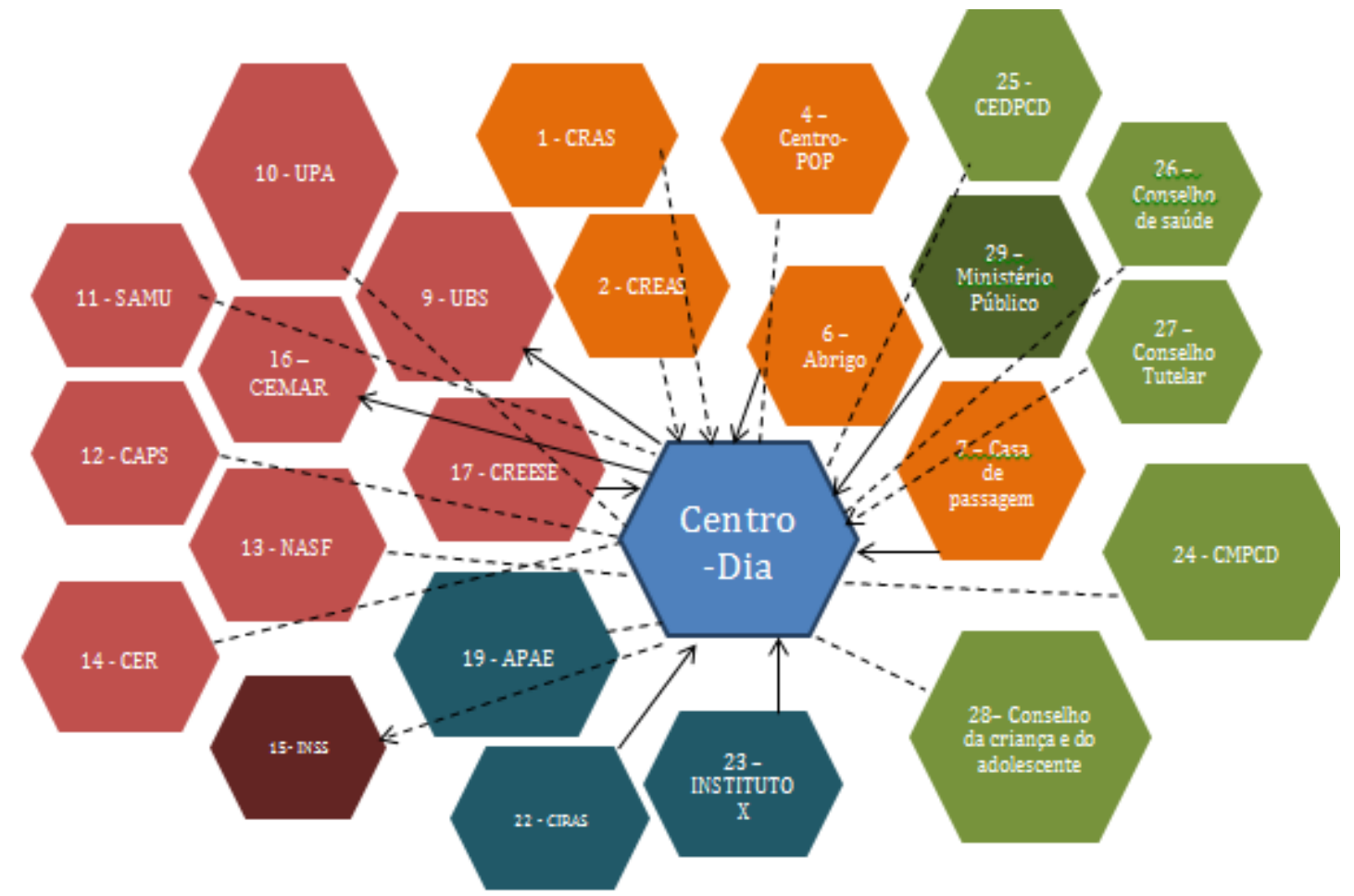

Figura 4: Configuração local da Rede de Proteção Social a Pessoa com Deficiência atendida no Centro-Dia da Cidade C.

Fonte: Autoria própria a partir da pesquisa de campo

As orientações técnicas do Centro-Dia preconizam que para o equipamento funcionar é necessário que se tenha uma boa articulação com um Creas de Referência e com o Nasf ou UBS, entretanto a representação da rede demonstra que a relação com o NASF é uma necessidade, mas não existe, conforme uma das declarações: "Essa articulação com a Rede, para a gente, não tem funcionado de forma nenhuma." (Assistente Social - Grupo Focal - Centro-Dia da cidade C).

Interessante observar que houve longo prazo entre a pactuação e implementação do serviço, mas isso não foi suficiente para garantir boas articulações. Tal fato remete a lógica de que a rede é uma variável dependente de resultados políticos e comportamentos organizacionais que servem para explicar seus desenhos (Raab, Kenis, 2007).

O Centro-Dia D, pactuado em março de 2013 e implementado desde maio de 2014, com execução indireta, atualmente contando com 28 usuários. Na figura 5, aponta-se uma configuração de rede composta por 25 organizações, porém, muitas com frágil articulação. Das listadas, aparecem apenas o Creas e os abrigos como equipamentos públicos de assistência social. Nas falas das entrevistas, destaca-se que:

A gente está trabalhando nessa questão da articulação de parceiros. Desde o princípio, a coordenadora tem trabalhado nessa questão de parcerias e tudo mais. Então, nesse trabalho já recebe encaminhamento do Cras e aqui tem como diferencial é que as pessoas que mesmo as que não participam do serviço, a gente presta orientações. [...] a gente já está tendo realmente esse diálogo com a saúde. E esse fluxo realmente já está começando a andar porque apresenta uma sensibilidade (Assistente Social - Grupo Focal - CD da cidade D). 
É mister que, mesmo com a execução de indireta, o que possivelmente poderia facilitar a comunicação com os serviços da rede privada ou filantrópica isso não ocorre, pois no fluxo desenhado aparece uma frágil articulação com a Associação de Pais e Amigos dos Excepcionais (Apae), por exemplo, denotando que a forma de execução pode ou não influenciar na articulação rede, seja ela de serviços público ou privado. Importante destacar, neste equipamento, que existe uma grande articulação com os equipamentos de cultura, esporte e lazer, o que também aparece fortemente nas entrevistas.

A setorialidade do policy making, no caso do Centro-dia D, propiciada, inclusive, pela sua execução por uma organização privada, se contrastada com a regulamentação do serviço pelo Estado, demonstra que a fragmentação e indistinção entre o público e o privado são elementos presentes nesta rede (Giulinni, 1998).

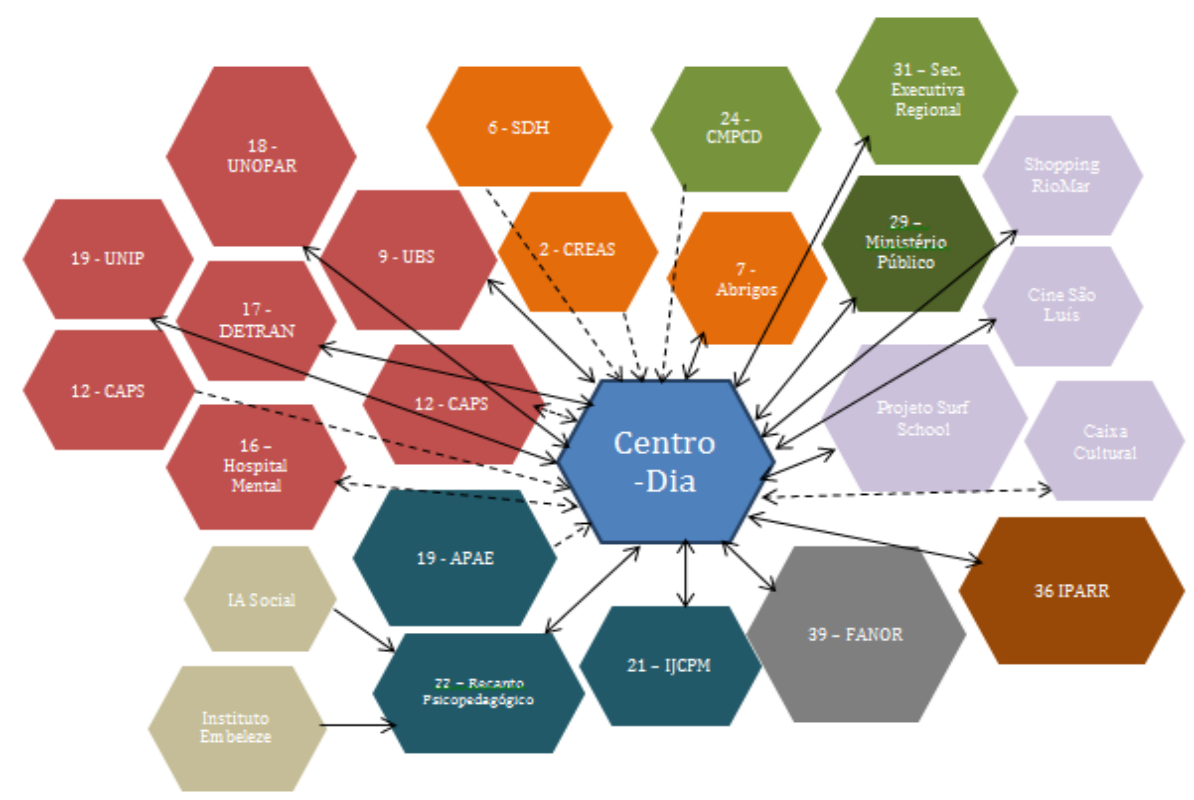

Figura 5: Configuração local da Rede de Proteção Social a Pessoa com Deficiência atendida no Centro-Dia da Cidade D

Fonte: Autoria própria a partir da pesquisa de campo

Por fim, no último fluxo analisado, o Centro-Dia E, que foi pactuado em novembro de 2012 e implementado em março de 2014, com execução indireta e, atualmente, contando com 22 usuários. Na figura 6, leva-se em consideração que, apesar do pouco tempo de funcionamento, se percebe que este equipamento tem uma grande perceptibilidade em relação a rede que está inserido, sendo listadas 25 organizações. Mesmo assim, são percebidas algumas fragilidades, que se dão, ao que parece, pelo fato de os equipamentos se fecharem para alguns trabalhos conjuntos: "Na verdade a gente percebe muita desarticulação. Eles se fecham! (Assistente Social - Grupo focal Centro-Dia E). Outra profissional também salienta que "Ao invés do Creas [...] chamar a gente para reunião e discutir... Não! Era a gente que chamava todo mundo aqui. Nós fizemos várias reuniões no início, com o Creas, com o pessoal da saúde de matriciamento e até com o Cras. [...] Mas, não funcionou!" (Psicóloga - Grupo Focal Centro-Dia E).

De uma forma geral, todos os equipamentos têm uma boa percepção da rede a qual fazem parte, da necessidade de uma boa comunicação entre os serviços, entretanto pode-se perceber que ainda existem relações muito frágeis. Na maioria dos casos, o tempo de funcionamento, como o tempo de planejamento para implementação, em alguns casos, denota influenciar a articulação da rede. Já a estrutura de execução, parece não inferir nas articulações nem entre os serviços públicos, quando se tem execução direta, nem entre os privados e filantrópicos quando a execução é indireta. 
Configurações locais da rede socioassistencial do SUAS, para a proteção social das pessoas com deficiência e suas famílias: olhares a partir dos Centros-Dia de referência na região Nordeste do

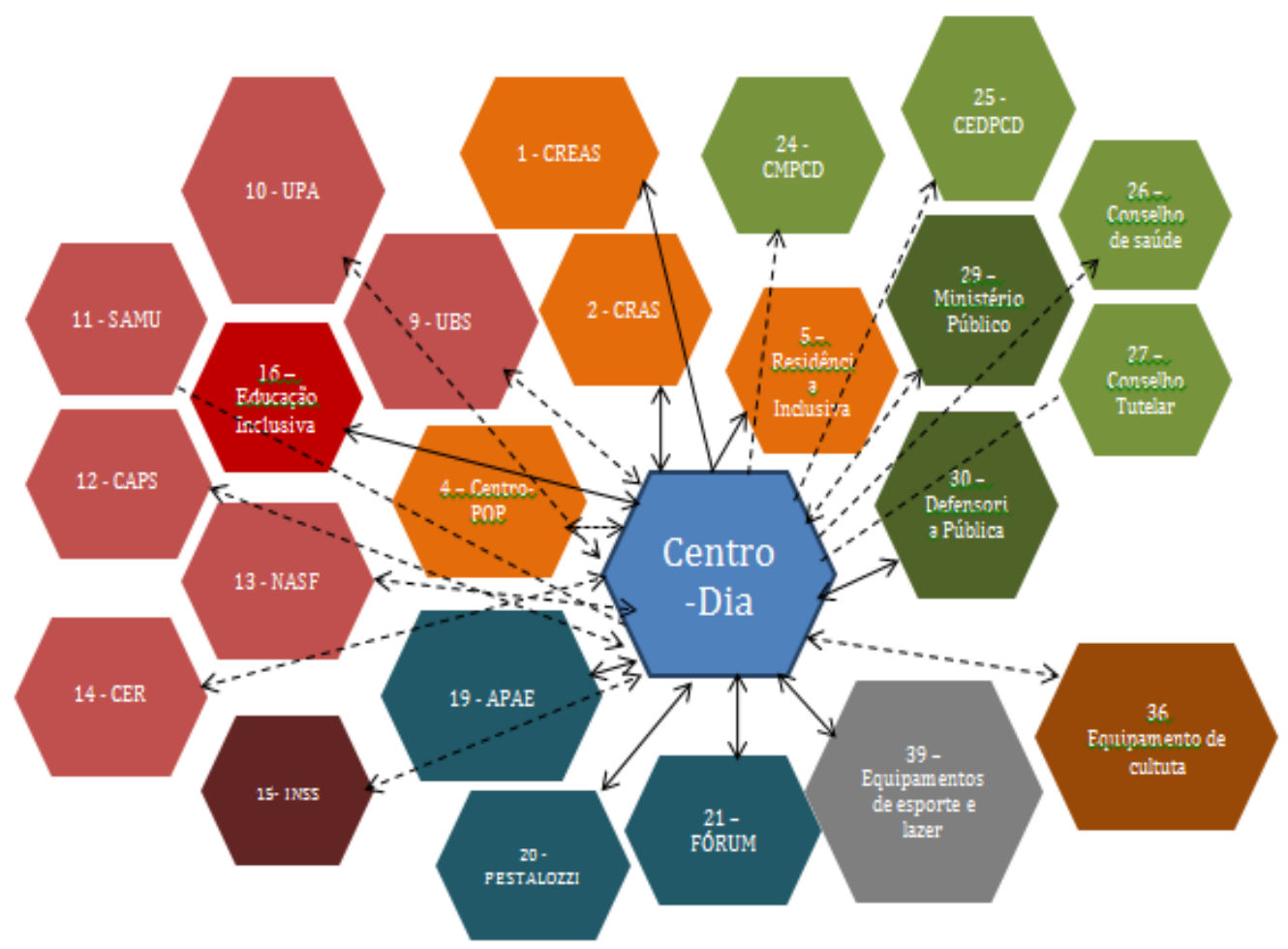

Figura 6: Configuração local da Rede de Proteção Social a Pessoa com Deficiência atendida no Centro Dia da Cidade E

Fonte: Autoria própria a partir da pesquisa de campo

\section{OS PONTOS CONVERGENTES E AS DISTINÇÕES NAS CONFIGURAÇÕES LOCAIS DA REDE}

A Rede Suas é diversa assim como as características territoriais (sociais, econômicas, políticas e culturais) dos municípios brasileiros de todos os portes. Tal pluralidade em si não se faz um problema, mas sim uma forma de garantir padrões necessários de qualidade para as ofertas da política de Assistência Social. Sabe-se que, acrescido a isso, diante da necessidade do alto grau de capacidade de colaboração públicoprivado e elevada capacidade de gestão de redes (Goldsmith, Eggers, 2011), tem-se graus de sucesso variados para as ofertas da policy que vêm sendo desenhadas e implementadas com base na premissa que a existência de institucionalidades e recursos (principalmente financeiros e humanos) consegue ser viável.

Corroborando com este aspecto, a seguir, são feitas algumas análises sobre as relações dos CentrosDia com os principais equipamentos prestadores de serviços da Rede Socioassistencial do Suas que são apresentados nos fluxos encaminhados. A figura 7 sintetiza as diferentes articulações apresentadas pelos cinco Centros-Dia com relação aos equipamentos da Rede Socioassistencial do Suas. 


\begin{tabular}{|c|c|c|c|c|c|}
\hline \multicolumn{6}{|c|}{ Equipamentos Públicos da Assistência Social } \\
\hline & $C D-A$ & $C D-B$ & $C D-C$ & $C D-D$ & $\mathrm{CD}-\mathrm{E}$ \\
\hline CRAS & $\begin{array}{l}\text { Forte Articulação } \\
\text { apenas de oferta }\end{array}$ & $\begin{array}{l}\text { Forte articulação de } \\
\text { demanda e oferta } \\
\text { entre as instituiç̄oses }\end{array}$ & $\begin{array}{l}\text { Frágil articulação } \\
\text { de demanda }\end{array}$ & - & $\begin{array}{c}\text { Forte articulação de } \\
\text { demanda e oferta entre as } \\
\text { instituiç̧ôes }\end{array}$ \\
\hline CREAS & $\begin{array}{l}\text { Forte articulação de } \\
\text { demanda e oferta } \\
\text { entre as instituiç̧̃es }\end{array}$ & $\begin{array}{l}\text { Forte articulação de } \\
\text { demanda e oferta } \\
\text { entre as instituiç̋̃es }\end{array}$ & $\begin{array}{l}\text { Frágil articulação } \\
\text { de demanda }\end{array}$ & $\begin{array}{l}\text { Frágil articulação de } \\
\text { demanda }\end{array}$ & $\begin{array}{l}\text { Forte articulação apenas } \\
\text { de oferta }\end{array}$ \\
\hline CREAS de Referência & & $\begin{array}{l}\text { Forte articulação de } \\
\text { demanda e oferta } \\
\text { entre as instituiç̋̃es }\end{array}$ & & & - \\
\hline Centro-POP & & $\begin{array}{l}\text { Forte articulacão } \\
\text { apenas de oferta }\end{array}$ & $\begin{array}{l}\text { Relação necessária } \\
\text { mas ainda } \\
\text { inexistente }\end{array}$ & & $\begin{array}{l}\text { Frágil articulação de } \\
\text { demanda e oferta entre as } \\
\text { instituiçổes }\end{array}$ \\
\hline Residência Inclusiva & $\begin{array}{l}\text { Forte articulação } \\
\text { apenas de oferta }\end{array}$ & $\begin{array}{c}\text { Relação } \\
\text { necessária, mas } \\
\text { ainda inexistente }\end{array}$ & & & $\begin{array}{l}\text { Forte articulação apenas } \\
\text { de oferta }\end{array}$ \\
\hline $\begin{array}{c}\text { Vigilância } \\
\text { Socioassistencial }\end{array}$ & & $\begin{array}{c}\text { Forte articulação } \\
\text { de demanda e } \\
\text { oferta entre as } \\
\text { instituições }\end{array}$ & - & & - \\
\hline
\end{tabular}

Figura 7: Síntese das articulações existentes entre os Centros-Dia com equipamentos/serviços da Rede

Socioassistencial do Suas

Fonte: Autoria própria

Legenda:

FORTE ARTICULAÇÃO apenas de oferta ou demanda de uma para outra instituição FORTE ARTICULAÇÃO de oferta e demanda entre as instituições

FRÁGIL ARTICULAÇÃO apenas de oferta ou demanda de uma para outra instituição

FRÁGIL ARTICULAÇÃO de oferta e demanda entre as instituições

RELAÇÃO NECESSÁRIA, mas ainda inexistente

Nos dois primeiros casos, Centros-Dia A e B, existem uma relação de oferta e demanda (entrada e saída) entre o Centro-Dia e o Creas denotando uma forte articulação quanto ao referenciamento do serviço. A ideia de referenciamento de serviço significa a lógica de entrada e encaminhamento do usuário que deve/pode ser feita pelo Cras ou Creas de um dado território, no sentido, inclusive, de garantir a universalidade do atendimento, ou implica no efetivo acompanhamento deste cidadão/família por um conjunto de organizações públicas e privadas. Cabe aqui destacar que foi listado no instrumento tanto o Creas como o Creas de Referência e apenas o Centro-Dia B o coloca e com forte relação de oferta e demanda. Apesar de no instrumento se fazer uma distinção entre Creas e Creas de Referência, pode ser que nas representações das redes não tenha ficado claro isso. Mas, mesmo assim, dois apresentaram a ideia de forte articulação de oferta e demanda entre os Centros-Dia e Creas (A e B), um apresentou forte relação de oferta (E) e dois apresentam frágil articulação (C e D).

Relacionado à articulação com as Residências Inclusivas, na PSE de Alta Complexidade, equipamentos novos, tais como os Centros-Dia, observa-se que prevalece articulações só de encaminhamento do Centro-Dia para o Residência Inclusiva. Nos demais percebe-se a necessidade de relação, mas esta ainda não existe.

No processo de análise dos dados, na figura 7, foi possível perceber que apenas o Centro-Dia B coloca com forte relação de oferta e demanda, os demais nem sequer citam. Esse é um fato curioso, uma vez que, a priori, caberia a todos os equipamentos da Rede Socioassistencial do Suas se municiarem de informações da Vigilância Socioassistencial, inclusive no sentido de identificar demandas e fazer busca ativa.

A figura 8 apresenta as diferentes articulações expostas pelos Centros-Dia com relação aos fluxos existentes com principais órgãos prestadores de serviços de outras políticas setoriais, tais como saúde e educação. 
Configurações locais da rede socioassistencial do SUAS, para a proteção social das pessoas com deficiência e suas famílias: olhares a partir dos Centros-Dia de referência na região Nordeste do

\begin{tabular}{|c|c|c|c|c|c|}
\hline \multicolumn{6}{|c|}{ Orgão e Serviços de Outras Políticas Setoriais (Saúde, Educação e outras) } \\
\hline & $\mathrm{CD}-\mathrm{A}$ & CD-B & $\mathrm{CD}-\mathrm{C}$ & $C D-D$ & $\mathrm{CD}-\mathrm{E}$ \\
\hline UBS- Unidade Básica de Saúde & $\begin{array}{l}\text { Frágil articulacǟo de } \\
\text { demanda }\end{array}$ & $\begin{array}{l}\text { Forte articulação apenas } \\
\text { de oferta }\end{array}$ & $\begin{array}{l}\text { Forte articulacão apenas } \\
\text { de oferta }\end{array}$ & $\begin{array}{l}\text { Forte articulacäo de } \\
\text { oferta e demanda } \\
\text { entre as instituiçõoes }\end{array}$ & Frágil articulaçäo de oferta \\
\hline $\begin{array}{l}\text { UPA - Unidade de Pronto } \\
\text { Atendimento }\end{array}$ & - & $\begin{array}{l}\text { Forte articulacão apenas } \\
\text { de oferta }\end{array}$ & - & - & $\begin{array}{c}\text { Frágil articulaçăo de oferta e } \\
\text { demanda entre as } \\
\text { instituicôes }\end{array}$ \\
\hline $\begin{array}{l}\text { SAMU - Servico de } \\
\text { Atendimento Móvel de Urgência }\end{array}$ & - & - & - & - & $\begin{array}{l}\text { Relaçǟo necessária, mas } \\
\text { ainda inexistente. }\end{array}$ \\
\hline $\begin{array}{l}\text { CAPS - Centro de Atenção } \\
\text { Psicossocial }\end{array}$ & $\begin{array}{l}\text { Forte articulacăo de oferta } \\
\text { e demanda entre as } \\
\text { instituigöes }\end{array}$ & $\begin{array}{c}\text { Forte articulaçäo de oferta } \\
\text { e demanda entre as } \\
\text { instituicões }\end{array}$ & $\begin{array}{l}\text { Relação necessária, mas } \\
\text { ainda inexistente. }\end{array}$ & $\begin{array}{l}\text { Frágil articulaçäo de } \\
\text { demanda }\end{array}$ & $\begin{array}{c}\text { Frágil articulaçäo de oferta } \\
\text { demanda entre as } \\
\text { instituicóes }\end{array}$ \\
\hline $\begin{array}{l}\text { NASF - Núdeo de Apoio a } \\
\text { Saúde da Familia }\end{array}$ & - & $\begin{array}{l}\text { Forte articulacäo de oferta } \\
\text { e demanda entre as } \\
\text { instituicóes }\end{array}$ & $\begin{array}{l}\text { Relacão necessária, mas } \\
\text { ainda inexistente. }\end{array}$ & - & $\begin{array}{c}\text { Frágil articulaç̄ó de oferta e } \\
\text { demanda entre as } \\
\text { instituiōos }\end{array}$ \\
\hline $\begin{array}{c}\text { CER - Centros Especializados } \\
\text { em Reabilitaçâo }\end{array}$ & $\begin{array}{l}\text { Forte articulacão apenas } \\
\text { de oferta }\end{array}$ & $\begin{array}{l}\text { Forte articulacäo de oferta } \\
\text { e demanda entre as } \\
\text { instituicóes }\end{array}$ & $\begin{array}{l}\text { Relação necessária, mas } \\
\text { ainda inexistente. }\end{array}$ & - & $\begin{array}{c}\text { Frágil articulaç̃o de oferta e } \\
\text { demanda entre as } \\
\text { instituicôes }\end{array}$ \\
\hline INSS & - & $\begin{array}{l}\text { Frágil articulacäo de oferta } \\
\text { e demanda entre as } \\
\text { instituicóes }\end{array}$ & $\begin{array}{l}\text { Frágil articulacão aoenas } \\
\text { de oferta }\end{array}$ & - & $\begin{array}{c}\text { Frágil articulaç̄o de oferta e } \\
\text { demanda entre as } \\
\text { instituiốes }\end{array}$ \\
\hline Hospital Mental & - & - & - & $\begin{array}{l}\text { Forte articulaçäo de } \\
\text { oferta e demanda } \\
\text { entre as instituicões }\end{array}$ & 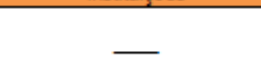 \\
\hline $\begin{array}{l}\text { Ed. Especial E Inclusiva } \\
\text { Estadual E Municipal }\end{array}$ & - & - & - & - & $\begin{array}{c}\text { Forte articulacäo de oferta e } \\
\text { demanda entre as } \\
\text { instituigóes }\end{array}$ \\
\hline Escolas Municipais e Estaduais & $\begin{array}{c}\text { Frágil articulaçâo de oferta } \\
\text { e demanda entre as } \\
\text { instituicōes }\end{array}$ & - & - & - & - \\
\hline $\begin{array}{l}\text { CREESE - Centro de Referência } \\
\text { em Educacäo Especial }\end{array}$ & - & - & $\begin{array}{l}\text { Forte articulaçäo apenas } \\
\text { de demanda }\end{array}$ & - & - \\
\hline
\end{tabular}

Figura 8: Síntese das articulações existentes entre os Centros-Dia, órgãos e serviços de outras políticas setoriais

Fonte: Autoria própria

Legenda:

FORTE ARTICULAÇÃO apenas de oferta ou demanda de uma para outra instituição
FORTE ARTICULAÇÃO de oferta e demanda entre as instituições
FRÁGIL ARTICULAÇÃO apenas de oferta ou demanda de uma para outra instituição
FRÁGIL ARTICULAÇÃO de oferta e demanda entre as instituições
RELAÇÃO NECESSARIA, mas ainda inexistente

Quando se observa a aproximação e o nível de articulação e integração entre os diferentes equipamentos públicos de Assistência Social com os de outras políticas setoriais, tais como saúde e educação, por exemplo, percebemos o quão frágeis ainda são os "nós" da Rede Suas. Isto fica evidente nas configurações apresentada na figura 8. As relações com os equipamentos da política de saúde aparecem mais fortemente no caso B. Nos casos A e B, as relações de oferta e demanda com o Caps aparecem forte. Entretanto, nos demais casos, nota-se uma grande fragilidade e até mesmo necessidade de se construir essa relação, situação do C. Os Centros-dia B e D, sequer são citados no Nasf que seria um pré-requisito para a pactuação com o Ministério do Desenvolvimento Social e Combate a Pobreza (MDS) para a abertura do serviço.

Com os equipamentos da política de educação, nota-se uma grande fragilidade e que apenas os casos A, C e E mencionam, cada um, uma instituição de ensino com algum tipo de relação. O Centro-Dia da cidade B relata que esta é uma busca importante.

Tais análises remontam a questões trazidas por Raab e Keines (2007) sobre a compreensão da rede como estrutura organizacional emergente, uma nova forma de organização social, que é mais que a soma de atores e suas relações, mais que uma combinação de hierarquia entre o público e privado. O "tipo ideal" de coordenação e funcionamento dos Centros-dia é algo que ainda parece estar em processo de construção.

A figura 9 apresenta as relações existentes ou não entre o Centro-Dia e as organizações privadas da sociedade civil. Por este, percebe-se que a Apae é a entidade que é colocada em todos os fluxos sendo estabelecidos diferentes tipos de relação. Em segundo lugar, aparece a Pestallozzi, citada por dois equipamentos. Mas, de modo geral, percebe-se que ainda há pouca ou nenhuma articulação com as entidades da sociedade civil, esta síntese apenas ratifica a análise exposta no tópico anterior, mostrando que a forma de execução (direta ou indireta) não infere muito nas possibilidades de articulação. Evidenciando que a Apae, por exemplo, só tem forte ligação com o Centro-Dia quando a mesma é a executora do serviço. 


\begin{tabular}{|c|c|c|c|c|c|}
\hline \multicolumn{6}{|c|}{ Organizaçöes Privadas da Sociedade Civil } \\
\hline & $\mathrm{CD}-\mathrm{A}$ & $\mathrm{CD}-\mathrm{B}$ & $\mathrm{CD}-\mathrm{C}$ & $C D-D$ & $\mathrm{CD}-\mathrm{E}$ \\
\hline $\begin{array}{l}\text { APAE - Associação de } \\
\text { Pais e Amigos dos } \\
\text { Excepcionais }\end{array}$ & $\begin{array}{l}\text { Frágil } \\
\text { articulação de } \\
\text { oferta }\end{array}$ & $\begin{array}{l}\text { Forte articulação } \\
\text { de oferta }\end{array}$ & $\begin{array}{c}\text { Relação } \\
\text { necessária, mas } \\
\text { ainda inexistente }\end{array}$ & $\begin{array}{c}\text { Frágil articulação de } \\
\text { demanda }\end{array}$ & $\begin{array}{c}\text { Frágil articulação de oferta e } \\
\text { demanda entre as } \\
\text { instituiçốes }\end{array}$ \\
\hline $\begin{array}{l}\text { PESTALOZZI - Centro } \\
\text { de Atendimento } \\
\text { Educacional } \\
\text { Especializado }\end{array}$ & 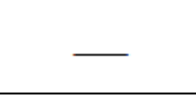 & $\begin{array}{l}\text { Forte articulação } \\
\text { de oferta }\end{array}$ & - & - & $\begin{array}{c}\text { Frágil articulação de oferta e } \\
\text { demanda entre as } \\
\text { instituiçốes }\end{array}$ \\
\hline $\begin{array}{l}\text { FORUM DE ENTIDADES } \\
\text { E PATOLOGIAS DE } \\
\text { PESSOAS COM } \\
\text { DEFICIENCIA } \\
\end{array}$ & - & - & 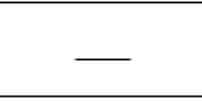 & - & $\begin{array}{c}\text { Forte articulação de oferta e } \\
\text { demanda entre as } \\
\text { instituições }\end{array}$ \\
\hline $\begin{array}{c}\text { ADOTE- } \\
\text { Associação de } \\
\text { Orientaçâo aos } \\
\text { Deficientes }\end{array}$ & $\begin{array}{l}\text { Forte articulação } \\
\text { de oferta }\end{array}$ & - & & - & - \\
\hline UNIP & {[} & - & $\longrightarrow$ & $\begin{array}{l}\text { Forte articulação de } \\
\text { oferta e demanda } \\
\text { entre as instituiçõoses }\end{array}$ & - \\
\hline UNOPAR & - & - & - & $\begin{array}{l}\text { Forte articulacâá de } \\
\text { oferta e demanda } \\
\text { entre as instituiç̧oses }\end{array}$ & - \\
\hline
\end{tabular}

Figura 9: Síntese das articulações existentes entre os Centros-Dia e organizações privadas da sociedade civil

Fonte: Autoria própria

Legenda:

FORTE ARTICULAÇÃO apenas de oferta ou demanda de uma para outra instituição FORTE ARTICULAÇÃO de oferta e demanda entre as instituições

FRÁGIL ARTICULAÇÃO apenas de oferta ou demanda de uma para outra instituição

FRÁGIL ARTICULAČ̃̃ de oferta e demanda entre as instituições

RELAÇÃO NECESSÁRIA, mas ainda inexistente

Na figura 10, é feita a análise que sintetiza o nível de relações existentes entre os Centros-Dia e os órgãos públicos de garantia de direitos e controle social.

Os órgãos de defesa e controle social, a partir dos casos analisados, denotam uma grande fragilidade nas relações com a maioria destes. É de se questionar como que um equipamento como o Centro-Dia não tem relação ou sequer cita os Conselhos de Assistência Social e poucos citam os Conselhos de Direito da Pessoa com Deficiência?

\begin{tabular}{|c|c|c|c|c|c|}
\hline \multicolumn{6}{|c|}{ Órgãos Públicos de Defesa de Direitos e Controle Social } \\
\hline & $\mathrm{CD}-\mathrm{A}$ & $\mathrm{CD}-\mathrm{B}$ & $\mathrm{CD}-\mathrm{C}$ & $C D-D$ & $C D-E$ \\
\hline $\begin{array}{l}\text { Conselho Municipal da } \\
\text { Pessoa com Deficiência }\end{array}$ & - & $\begin{array}{c}\text { Relação } \\
\text { necessária, mas } \\
\text { ainda inexistente }\end{array}$ & $\begin{array}{l}\text { Relação necessária, } \\
\text { mas ainda } \\
\text { inexistente }\end{array}$ & $\begin{array}{l}\text { Frágil articulação de } \\
\text { demanda entre as } \\
\text { instituições }\end{array}$ & $\begin{array}{l}\text { Forte articulação de oferta e } \\
\text { demanda entre as instituições }\end{array}$ \\
\hline $\begin{array}{l}\text { Conselho Estadual dos } \\
\text { Direitos da Pessoa com } \\
\text { Deficiência }\end{array}$ & & $\begin{array}{c}\text { Relacão } \\
\text { necessária, mas } \\
\text { ainda inexistente }\end{array}$ & $\begin{array}{l}\text { Relacão necessária. } \\
\text { mas ainda } \\
\text { inexistente }\end{array}$ & - & $\begin{array}{l}\text { Forte articulação de oferta e } \\
\text { demanda entre as instituições }\end{array}$ \\
\hline Conselho de Saúde & & $\begin{array}{c}\text { Relação } \\
\text { necessária, mas } \\
\text { ainda inexistente }\end{array}$ & $\begin{array}{c}\text { Relação necessária, } \\
\text { mas ainda } \\
\text { inexistente }\end{array}$ & - & $\begin{array}{l}\text { Frágil articulação de oferta e } \\
\text { demanda entre as instituições }\end{array}$ \\
\hline Conselho Tutelar & & & $\begin{array}{c}\text { Frágil articulação de } \\
\text { oferta entre as } \\
\text { instituiçốes }\end{array}$ & - & $\begin{array}{l}\text { Relação necessária, mas } \\
\text { ainda inexistente }\end{array}$ \\
\hline $\begin{array}{l}\text { Conselho da Criança e } \\
\text { Adolescente }\end{array}$ & & $\begin{array}{c}\text { Relação } \\
\text { necessária, mas } \\
\text { ainda inexistente }\end{array}$ & $\begin{array}{l}\text { Relação necessária, } \\
\text { mas ainda } \\
\text { inexistente }\end{array}$ & - & \\
\hline MP - Ministério Público & $\begin{array}{c}\text { Fráqil articulacão } \\
\text { de demanda } \\
\text { entre as } \\
\text { instituiçôes } \\
\end{array}$ & - & $\begin{array}{l}\text { Forte articulação de } \\
\text { demanda entre as } \\
\text { instituições }\end{array}$ & $\begin{array}{l}\text { Forte articulação de } \\
\text { demanda e oferta } \\
\text { entre as instituiçỗes }\end{array}$ & $\begin{array}{l}\text { Frágil articulação de demanda } \\
\text { e oferta entre as instituições }\end{array}$ \\
\hline Defensoria Pública & - & - & - & - & $\begin{array}{l}\text { Forte articulação de demanda } \\
\text { e oferta entre as instituiçôes }\end{array}$ \\
\hline
\end{tabular}

Figura 10: Síntese do nível de relação existente entre os Centros-Dia e os órgãos públicos de garantia de direitos e controle social

Fonte: Autoria própria

Legenda:

FORTE ARTICULAÇÃO apenas de oferta ou demanda de uma para outra instituição

FORTE ARTICULAÇÃO de oferta e demanda entre as instituições

FRÁGIL ARTICULAÇÃO apenas de oferta ou demanda de uma para outra instituição

FRÁGIL ARTICULAÇÃO de oferta e demanda entre as instituições

RELAÇÃO NECESSÁRIA, mas ainda inexistente 
Configurações locais da rede socioassistencial do SUAS, para a proteção social das pessoas com deficiência e suas famílias: olhares a partir dos Centros-Dia de referência na região Nordeste do

A maioria dos casos percebe os conselhos como uma relação necessária, mas ainda inexistente. Esta questão aparece, inclusive, nas entrevistas: "Geralmente, o Conselho da Pessoa com Deficiência forma parcerias, um assento esporadicamente, um grupo que realiza atividades específicas. Há algum tempo, a gente teve capacitações, mas, atualmente, não está acontecendo.” (Gestora do Creas - Centro-Dia E).

Com o Ministério Público, um órgão de defesa de direitos que deve estar por dentro dos debates e das ações da Assistência Social nos municípios, a situação não é muito diferente. Quando se tem ligação com o Centro-Dia é numa perspectiva que falta clareza do que é o serviço. Entretanto, é fundamental estabelecer bons e transparentes relacionamentos com este órgão que, em sua maioria, encaminha demandas para o Suas, mas que também pode ser demandado.

Por fim, na figura 11 aparece a síntese de outras parcerias existentes entre os Centros-Dia e os equipamentos de cultura, esporte e lazer.

Percebe-se que, nos casos B, D e E, os equipamentos conseguem articular outras parcerias como, por exemplo, com equipamentos de cultura, esporte e lazer. Isso representa um avanço e é importante para o desempenho dos usuários do serviço.

\begin{tabular}{|c|c|c|c|c|c|}
\hline \multicolumn{6}{|c|}{ Equipamentos de cultura, esporte e lazer. } \\
\hline & $C D-A$ & $\mathrm{CD}-\mathrm{B}$ & $\mathrm{CD}-\mathrm{C}$ & $C D-D$ & $C D-E$ \\
\hline Pontos Turisticos & & $\begin{array}{c}\text { Forte } \\
\text { articulação de } \\
\text { oferta entre as } \\
\text { instituições }\end{array}$ & & $\begin{array}{l}\text { Forte articulação de } \\
\text { oferta e demanda } \\
\text { entre as instituiçôes }\end{array}$ & $\begin{array}{l}\text { Forte articulação de oferta e } \\
\text { demanda entre as } \\
\text { instituições }\end{array}$ \\
\hline Praças & & $\begin{array}{c}\text { Forte } \\
\text { articulação de } \\
\text { oferta entre as } \\
\text { instituições }\end{array}$ & & $\begin{array}{l}\text { Forte articulacão de } \\
\text { oferta e demanda } \\
\text { entre as instituições }\end{array}$ & $\begin{array}{l}\text { Forte articulacão de oferta e } \\
\text { demanda entre as } \\
\text { instituições }\end{array}$ \\
\hline Jardim Zoológico & & $\begin{array}{c}\text { Forte } \\
\text { articulação de } \\
\text { oferta entre as } \\
\text { instituições }\end{array}$ & & & $\begin{array}{l}\text { Forte articulação de oferta e } \\
\text { demanda entre as } \\
\text { instituições }\end{array}$ \\
\hline Acesso Cidadão & & $\begin{array}{c}\text { Forte } \\
\text { articulação de } \\
\text { oferta entre as } \\
\text { instituições }\end{array}$ & & & $\begin{array}{c}\text { Forte articulação de oferta e } \\
\text { demanda entre as } \\
\text { instituiçõos }\end{array}$ \\
\hline $\begin{array}{l}\text { Estação Ciência } \\
\text { (Cultura) }\end{array}$ & & $\begin{array}{c}\text { Forte } \\
\text { articulação de } \\
\text { oferta entre as } \\
\text { instituições }\end{array}$ & 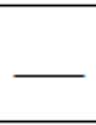 & 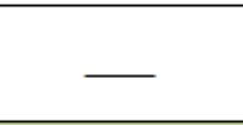 & $\begin{array}{l}\text { Frágil articulação de oferta e } \\
\text { demanda entre as } \\
\text { instituições }\end{array}$ \\
\hline Projeto Surf School & & & & $\begin{array}{l}\text { Forte articulação de } \\
\text { oferta e demanda } \\
\text { entre as instituicões }\end{array}$ & $\longrightarrow$ \\
\hline
\end{tabular}

Figura 11: Síntese das articulações existente entre os Centros-Dia e os equipamentos de cultura, esporte e lazer Fonte: Autoria própria

Legenda:

FORTE ARTICULAÇÃO apenas de oferta ou demanda de uma para outra instituição
FORTE ARTICULAÇÃO de oferta e demanda entre as instituições
FRÁGIL ARTICULAÇÃO apenas de oferta ou demanda de uma para outra instituição
FRÁGIL ARTICULAÇÃO de oferta e demanda entre as instituições
RELAÇÃO NECESSÂRIA, mas ainda inexistente

Percebe-se que a articulação territorial com equipamentos públicos e outras organizações privadas mais tem sido uma preocupação operacional dos executores dos serviços do que, necessariamente, ações estratégicas dos gestores municipais da Assistência Social. Tais questões levam a entender que atores fragmentados, públicos e privados, nenhum deles dotados de recursos suficientes, se confrontam sobre uma base voluntária, impulsionados por motivações intelectuais ou emotivas, com o objetivo de "minimizar as surpresas" decisionais. Não existe um locus privilegiado para a ação destes atores e as interações entre eles são caracterizadas pela cooperação voltada para o comum interesse de continuar "sendo importante do processo', ou seja, de continuar inserido na produção e na troca das informações úteis à gestão e ao reforço do próprio setor onde eles estão inseridos. (Regonini, 1989 apud Giuliani, 1998)

A partir da análise dos resultados, foi possível construir um quadro sintetizando as diferentes configurações locais de Proteção Social para pessoas com deficiência atendidas em Centro-Dia: 
Quando de síntese das relações existentes em cada Centro-Dia

\begin{tabular}{|c|c|c|c|c|c|}
\hline & $\mathbf{C D}-\mathbf{A}$ & CD - B & CD - C & CD - D & CD - E \\
\hline Rede Suas & 3 & 6 & 5 & 2 & 4 \\
\hline Saúde & 3 & 7 & 8 & 4 & 6 \\
\hline Educação & 1 & 0 & 0 & 3 & 1 \\
\hline $\begin{array}{l}\text { Organizações } \\
\text { Privadas }\end{array}$ & 3 & 2 & 3 & 7 & 3 \\
\hline $\begin{array}{l}\text { Órgão de defesa de } \\
\text { direitos e controle } \\
\text { social }\end{array}$ & 1 & 3 & 7 & 4 & 7 \\
\hline $\begin{array}{l}\text { Cultura, esporte e } \\
\text { lazer }\end{array}$ & 0 & 5 & 0 & 5 & 2 \\
\hline Total & 11 & 23 & 23 & 25 & 23 \\
\hline
\end{tabular}

Figura 12: Síntese das configurações locais existente na proteção social para pessoas com deficiência em cinco capitais da Região Nordeste.

Fonte: Autoria própria

Com base na figura 12 , pode-se perceber que a quantidade de instituições que os Centros-Dia declaram se relacionar ou ter a intenção de se relacionar está, em média, de 23, o que é bastante considerável. É interessante observar que estes equipamentos foram implementados em diferentes momentos entre os anos de 2012 e 2015 e que suas articulações podem ser mais fortes ou mais fracas a depender não apenas do tempo de abertura, mas também do empenho e da qualidade das relações políticas existentes no município.

Ao observar a aproximação e o nível de articulação e integração entre os diferentes equipamentos públicos de Assistência Social, percebemos o quão frágeis ainda são os "nós" da Rede Suas. De modo geral, percebe-se que os desafios postos à gestão em rede e o que é desafiado são as próprias configurações da rede no caso do Suas (Araujo, 2015).

Quando observadas as relações com as entidades e organizações privadas, a questão vem evoluindo de modo distinto nos diferentes municípios, dependendo bastante das relações locais entre os diferentes atores. Mesmo quando há uma boa relação e clareza de complementaridade na oferta dos serviços, frente as assimetrias que possam prevalecer nas relações entre o público e o privado, um dos principais desafios apontados é quanto a necessidade de uniformidade sobre a noção de referenciamento e contrarreferenciamento na Rede Suas (Araujo, 2015b).

\section{CONSIDERAÇÕES FINAIS}

Neste trabalho, foi possível perceber que na rede de proteção social para pessoas com deficiência atendidas em Centro-Dia, este equipamento foi apresentado como uma solução inovadora no conjunto de serviços socioassistenciais no Brasil e é entendido, no discurso explícito, por compreender pessoas com deficiência, de acordo com Cdpd; bem como pelo desenho proposto em que se cria um equipamento para execução de um dos serviços tipificados desde 2009, no âmbito do Suas (Boullosa, 2013).

Além disso, retomando o conceito de rede na teoria da policy network, que embasou este trabalho, a Rede Suas, considerada uma política intersetorial, ainda está em processo de construção. Não se pode afirmar que esta já funciona efetivamente, por motivos óbvios que vão desde as dificuldades de diálogo intra e interssetorial, devido as relações de poder e tentativa de minimizar hierarquias, como apontado na literatura. Isto se evidencia nos resultados da pesquisa, na qual o Centro-Dia, embora seja um equipamento novo, tem encontrado dificuldades para efetivar um trabalho articulado, inclusive dentro da própria rede de proteção social para pessoas com deficiência. De uma forma geral, nos cinco casos estudados, há uma boa percepção da rede na qual estão inseridos, entretanto, falta uma maior convicção sobre quais relações devem ser estabelecidas, seus níveis de intensidade e pactuação.

É mister aqui destacar que muitos são os desafios do trabalho em rede e não foi difícil percebê-los nos resultados deste trabalho. Há uma necessidade da real integração intragovernamental em todos os níveis, 
Configurações locais da rede socioassistencial do SUAS, para a proteção social das pessoas com deficiência e suas famílias: olhares a partir dos Centros-Dia de referência na região Nordeste do

principalmente, com as políticas de educação e saúde. Os serviços de educação quase não aparecem nos fluxos das redes percebidas pelas equipes técnicas e gestores dos Centros-Dia. No âmbito do Suas, os Centros-dia demandam ainda uma mudança de fluxos e de processos para serem integrados à rede como um todo e, em específico, a comunicação do Centro-Dia com os demais serviços da rede socioassistencial. Vale ressaltar ainda que, mesmo tendo convicta noção do que se propõe este recente equipamento, tem-se que lutar para um efetivo funcionamento da rede, para que o mesmo possa atingir suas metas e não se tornar apenas mais um serviço desarticulado e que não atenda as reais necessidades das pessoas com deficiência e suas famílias. Considera-se que este trabalho é apenas parte desse debate, e pontua ser pertinente que novos estudos sejam feitos a fim de fortalecer a importância da policy network do Suas. A não devolutiva das narrativas explicativas sobre os desenhos que expressaram as relações em rede pode ter trazido algum tipo de limitação na análise do estudo, uma vez que foi feita a interpretação pelos pesquisadores apenas pelas imagens desenhadas. Algo interessante a ser observado diz respeito a aprofundar como se estabelecem as relações em rede em cada contexto, observando questões legais, política e técnicas. Sugere-se que o instrumento de pesquisa utilizado, considerado como algo inovador para análises qualitativas sobre redes, possa ser aplicado em outros serviços socioassistenciais e com a mediação dos pesquisadores na aplicação, de modo a ter maior padronização das respostas destes para facilitar as análises.

Enfim, o estudo aqui exposto não encerra a discussão sobre as configurações da rede de proteção social para pessoas atendidas em Centros-Dia, considerando a complexidade da implementação destes instrumentos de políticas públicas, dado o caráter inovador dos serviços socioassistenciais e a diversidade de contextos existentes no Suas no âmbito local. Salienta-se, ainda, que a pesquisa, além de testar um instrumento de fácil entendimento de mapeamento de redes, contribui para o entendimento do Suas como estrutura analítica e ferramenta empírica, bem como como uma nova estrutura social (Raab, Kenis, 2007), com suas diferentes características dentro de um sistema federativo único de políticas públicas, que, na prática, demonstra não ser uniforme. Se, por um lado, a fluidez da rede é necessária para que novos serviços socioassistenciais sejam implementados, por outro, é preciso uma mudança de padrões culturais que compreendam necessidades de funcionamento mais horizontais, entre as diferentes políticas setoriais e entre órgãos públicos e organizações privadas. Deste modo, desenhou-se um quadro analítico da realidade dos Centros-dia no contexto da Rede Suas no Nordeste, com relação a implementação deste novo equipamento e serviço socioassistencial.

\section{REFERÊNCIAS}

Alter, C., Hage, J.(1993) Organizations working together. Newbury Park: Sage.

Araújo, E. T. (2015) Avaliação do processo de implementação dos Centros-dia de Referência para a Pessoa com Deficiência e suas Famílias, no âmbito do Plano Viver Sem Limite, na Região Nordeste. Relatório Final de Pesquisa. Projeto apoiado pela chamada pública Mcti-CNPq/MDS-Sagi No 24/2013 - Desenvolvimento Social, no Tema 1: Assistência Social - 1.6 A Implementação do Plano Viver Sem Limites, Ago.

Araújo, E. T., Boullosa, R. F.(2015) Avaliação da implementação do Centro-Dia para Pessoas com Deficiência: entre inovação e aprendizagem em políticas públicas. Interfaces Científicas - Humanas e Sociais, 3(3), Aracaju: Unit, 123 - 136, Jun.

Araújo, E., Cruz, D. L. (2013) Orientações técnicas sobre o Serviço de Proteção Social Especial para as pessoas com deficiência e suas famílias ofertado em Centros-Dia de Referência: metodologias e técnicas acessíveis no serviço. Brasília: Ministério do Desenvolvimento Social e Combate à Fome, Pnud, 179.

Convenção sobre os Direitos da Pessoa com Deficiência (2007). Protocolo facultativo à Convenção sobre os Direitos da Pessoa com Deficiência. Decreto legislativo $n^{\circ}$. 186, de 09 de julho de 2008: Decreto ${ }^{\circ}$. 6.949, de 25 de agosto de 2009, (4 ed.), ver e atual. - Brasília: Secretaria Nacional dos Direitos Humanos, Secretaria Nacional de Promoção dos Direitos da Pessoa com Deficiência, 2012b.

Boullosa, R. de F.(2013) O Suas e a proteção social especial para a pessoa com deficiência: um caso de inovação em políticas públicas? In: Congreso Internacional 29 del Clad sobre la Reforma del Estado y de la Administración Pública, 18, Anais....Montevideo, Uruguay, 29 oct. - 1 nov.

Bulhosa, R. R.(2015) Conselhos gestores e a lógica de formação de grupos: O Caso do Conselho Nacional de Juventude (Conjuve). 76f. Dissertação (Mestrado Multidisciplinar e Profissional em Desenvolvimento e

Revista de Gestão Social e Ambiental - RGSA, São Paulo, v. 11, n. 3, p. 73-91, set./dez. 2017. 
Gestão Social) - Programa de Desenvolvimento e Gestão Social da Universidade Federal da Bahia, Salvador/BA.

Giuliani, M. (1998) Policy network, In: Capano, G., Giuliano, M. Politiche Pubbliche. In: . Dizionario di politiche pubbliche. (2 ed.) Roma: Caroci Ed.

Goldsmith, S., Eggers, W.(2011) Governar em Rede. O novo formato do setor público. Brasília/São Paulo: Enap/Unesp.

Kenis, P., Schineider, V.(1991) Policy networks and policy analysis: scrutinizing a new analytical toolbox. In: Marin, B., Mayntz, R. (eds). Policy networks. Empirical evidence and theoretical considerations, Boulder/Colorado, Frankfurt: Campus Verlag/Westview Press, 25-62.

Lascoumes, P., LE Galès, P.(2007) Governance. International Journal of Policy, Administration, and Institutions, 20(1), USA: Blackwell Publishing, 1-21, jan.

(2012) Sociologia da ação pública. Tradução e estudo introdutório: George Sarmento, Maceió: Edufal.

Raab, J., Kenis, P.(2007) Taking stock of policy networks: do they matter? In: Fisher, F.,

Miller, G., Mara, S. (ed). Handbook of public policy analysis: theory, politics, and methods. Londres: Taylos $\&$ Francis Group, CRC.

\section{NOTAS}

${ }^{1}$ No período da avaliação da implementação dos Centros-dia, entre dezembro de 2013 e agosto de 2015, considerou-se cinco Centros-dia implementados, tendo em vista que o de Fortaleza-CE, inaugurou apenas em maio de 2015, quando já havia sido feita a coleta de dados. Assim, para efeito desta nova pesquisa, considerou-se também apenas os equipamentos nos quais se realizaram entrevistas e grupos focais com as equipes implementadoras e que permaneceram até o momento da aplicação do instrumento de coleta de percepções da rede socioassistencial, uma vez que foram utilizados conteúdos destas para as análises aqui apresentadas.

${ }^{2} \mathrm{Na}$ abordagem sociopolítica, os instrumentos de política pública são um tipo especial de instituição política que se configura como dispositivos técnicos e sociais que organizam relações sociais entre o poder público e seus destinatários (policytakers) em razão de representações e significados que são portadores com relação ao enfrentamento de um problema público (Lascoumes, LE Galès, 2004 apud Lascoumes, LE Galès, 2012).

${ }^{3}$ De acordo com a Tipificação Nacional de Serviço Socioassistenciais (Resolução do Conselho Nacional de Assistência Social (Cnas) no. 109, de 11 de novembro de 2009) existem 15 serviços a serem ofertados, sendo cinco destes na Proteção Social de Média Complexidade, estando entre estes o "Serviço de Proteção Social Especial para Pessoas com Deficiência, Idosas e suas Famílias", que são ofertados em Centros-Dia e em equipamentos referenciados. É importante destacar que o serviço foi tipificado em 2009, porém o detalhamento do seu design só é feito em 2012, a partir da "janela de oportunidades" criada pelo Plano Viver Sem Limite.

Data da submissão: 16/10/2016

Data de aceite: 25/09/2017 